\title{
Flattering and Unflattering Personality Portraits of Integratively Simple and Complex Managers
}

\author{
Philip E. Tetlock, Randall S. Peterson, and Jane M. Berry
}

\begin{abstract}
Research has revealed a good deal about both the situational determinants and judgmental and behavioral consequences of integrative complexity. Little is known, however, about people who are prone to think in integratively simple or complex ways. The present study fills this gap by drawing on data collected during in-depth assessments of master of business administration candidates. Integrative complexity was correlated with a broad range of self-report, observer-rating, semiprojective, and managerial-simulation measures. Results revealed a more complex pattern of correlates than one would expect from the flattering theoretical portrayals of integrative complexity. On self-report measures, complex persons scored higher on openness and creativity and lower on social compliance and conscientiousness. On personality-observer ratings, they emerged as narcissistic and somewhat antagonistic. On managerial-observer ratings, complex persons emerged as higher on initiative and self-objectivity. On semiprojective measures, complex persons scored higher on power motivation. The integratively complex manager is reminiscent of creative architects, scientists, and writers who participated in previous assessments over the past 3 decades.
\end{abstract}

The integrative complexity construct was originally conceived as an attempt to capture individual differences in styles of social thinking (Schroder, 1971; Schroder, Driver, \& Streufert, 1967; Streufert \& Streufert, 1978; Tetlock \& Suedfeld, 1988). Some people, it was posited, dislike ambiguity and dissonance and seek rapid cognitive closure in judging others and in making decisions. They form dichotomous (good vs. bad) impressions of people, events, and issues. Other people, it was posited, adopt more flexible, open-minded, and multidimensional stances toward the social world. These people recognize that life abounds with inconsistencies and contradictions. In this view, the intentions underlying behavior often consist of complex mixtures of motives (some good and some bad), making decisions often requires balancing conflicting goals, and life itself is a process of continual change that requires frequent updating of basic assumptions and beliefs.

The early efforts to assess individual differences in integrative complexity (or conceptual complexity as it was then known) relied heavily on the semiprojective Paragraph Completion Test (Schroder et al., 1967; Schroder \& Suedfeld, 1971). Subjects were presented with sentence stems that were focused on issues

Philip E. Tetlock, Randall S. Peterson, and Jane M. Berry, Institute of Personality and Social Research, University of California, Berkeley.

These data were collected as part of a series of 3-day assessments conducted by the faculty, staff, and graduate students of the Institute of Personality and Social Research. We especially acknowledge the contributions of Ken Craik, Charles O'Reilly, Oliver John, Barry Staw, and Sheldon Zedeck in making these assessments possible. We also thank Jenny Chatman, Wallace Hall, and three anonymous reviewers for thoughtful comments on a draft of the article.

Correspondence concerning this article should be addressed to Philip E. Tetlock, Institute of Personality and Social Research, University of California, Oxford Court Building, Room 2C, 2150 Kittredge Street, Berkeley, California 94720. of interpersonal conflict (When I am criticized, . . ), societal authority (Rules, . . .), and decisional ambiguity (When I am in doubt, . . .). Their task was to complete each stem and to write at least one additional sentence. The responses were then scored by trained coders on a 7-point complexity continuum that was defined by two cognitive stylistic indicators: evaluative differentiation (the capacity and willingness to tolerate different points of view) and conceptual integration (the capacity and willingness to generate linkages between points of view, to understand why different people look at the same event in different ways, to confront trade-offs, and to appreciate interactive patterns of causation). Low scores reflected low differentiation and integration (denial of ambiguity and shades of grey and dichotomous good--bad thinking), moderate scores reflected moderate differentiation but no integration (recognition of divergent viewpoints but no means of synthesizing or tying perspectives together), and high scores reflected both high differentiation and integration (explicit attempts to grapple with contradictions, to understand their sources, and to cope with their consequences).

This initial wave of research identified a variety of behavioral correlates of integrative complexity. Persons classified as dispositionally complex were more tolerant of incongruous trait combinations in an impression-formation task, more likely to use a variety of information in making decisions in Inter-Nation Simulations (Schroder et al., 1967), more likely to reach mutually beneficial compromise agreements in mixed motive games (Pruitt \& Lewis, 1975), and less likely to engage in justificatory attitude change in forced compliance experiments (for a review, see Streufert \& Streufert, 1978).

Relatively little was learned, however, about personality and life history correlates of integrative complexity. Beyond scattered reports of low-level correlations in expected directions with intelligence and with other cognitive stylistic variables (dogmatism, tolerance for ambiguity, and authoritarianism), vir- 
tually no data accumulated concerning self-report and observer rating correlates of integrative complexity. Instead, the research literature turned in two quite different directions. One line of work focused on situational determinants of integrative complexity of functioning, with an emphasis on environmental stressors (time, threats, and information load), accountability demands, and value conflict (Streufert \& Streufert, 1978; Suedfeld, 1992; Tetlock, 1983, 1985, 1986; Tetlock \& Boettger, 1989; Tetlock \& Kim, 1987). This work treated integrative complexity as a domain-specific and situation-specific construct (although it did not preclude the possibility of systematic individual differences). The second line of work moved in an archival direction. Investigators exploited the adaptability of the integrative complexity coding system to apply it to a variety of historical figures, from Cromwell to Gorbachev, and a variety of textual materials, from Supreme Court opinions to diplomatic communications to personal letters (Suedfeld \& Rank, 1976; Suedfeld \& Tetlock, 1977; Tetlock, 1981, 1983, 1984, 1985, 1989). This work shed light on the conditions under which people can be motivated to think in integratively complex ways as well as the conditions under which complex thinking is likely to prove adaptive.

Without denying the importance of these research trends, we do wish to call attention to some unfinished empirical business: the question of personality correlates of integrative complexity. Although we have learned a good deal about both the situational determinants and judgmental consequences of integrative complexity, we know nothing more than we did 20 years ago about the types of people who are prone to think in integratively simple versus complex ways.

The most widely held view of integrative complexity appears to be the more, the better. On its face, integratively complex thinkers, that is, people who understand divergent perspectives and try to reach integrative solutions, are better positioned to cope with the conflicting cross-pressures of life (intimacy vs. autonomy, work vs. leisure vs. family, savings vs. consumption, task vs. socioemotional leadership, etc.). Consider, for instance, the following expressions of scientific opinion on the issue:

1. Perry (1970) measured cognitive and ethical development among college students on a 9-point scale that defined growth as the emergence of progressively more differentiated and integrated ways of thinking about life-a view of cognitive development with obvious biological analogues (Werner, 1948). At the simple end of the scale, students think in terms of sharp "wethey" contrasts; at the complex end, they show tolerance of alternative ways of living, recognize tensions among objectives, and see life as a process of balancing competing goals and perspectives.

2. McAdams (1990) was admirably explicit in stating his own normative perspective on integrative complexity. He maintained that a "nonevaluative position" cannot be taken with respect to integrative complexity: "Here, complexity is superior to simplicity. The person who is integratively complex sees the world in more sophisticated terms, making more distinctions between various things and ideas (differentiation) and seeing more connections (integration)" (pp. 552-553).

3. Loevinger's (1976) influential theory of ego development carries a similar normative message. The lowest levels of development are characterized by reliance on integratively simple decision rules of an impulsive and egocentric nature ("I want this so I should have it") or of an authoritarian nature ("The rules say I should do this so I will"). The highest levels of ego development are characterized by tolerance for different ways of living and a "mature" understanding of the need to respect both human individuality and interdependence.

4. In a similar vein, Kohlberg's (1981) theory of moral development depicts a continuum that ranges from Stages I and II (simple reasoning driven by the reward-punishment contingencies of the social environment) to Stages V and VI (complex reasoning that requires a capacity to take the perspectives of others, to differentiate standards of self and of community, and to recognize trade-offs among competing principles). This convergence across research traditions is not, moreover, limited to formal theoretical statements; measures of integrative complexity, ego development, and Kohlbergian moral development are, indeed, moderately intercorrelated in the predicted directions (de Vries \& Walker, 1986; Sullivan, McCullough, \& Stager, 1970).

Tetlock $(1989,1991)$, however, takes a different tack and argues that it is too simple to conclude that complexity is inherently superior to simplicity (see also Schroder \& Suedfeld, 1971; Suedfeld, 1992). He proposes four sets of individual-difference hypotheses with respect to integrative complexity-hypotheses that can be organized into a $2 \times 2$ Peabody (1967) plot of flattering and unflattering portraits of simple versus complex thinkers. These personality portraits are grounded partly in empirical evidence (work on the causes, correlates, and consequences of integrative complexity) and partly in philosophical world views (Is the world a fundamentally simple or complex place? When does "good judgment" require acknowledging subtle trade-offs as opposed to taking a decisive or principled stand?). The portraits reveal that one can make strong prima facie functionalist cases that either integrative simplicity or complexity can be highly adaptive or maladaptive, depending on the problems confronting the individual and the personal and even moral values of the observer.

The flattering portrait of integratively complex thinkers emphasizes their willingness to refrain from jumping to conclusions in response to ambiguous evidence as well as their willingness to change their minds in response to contradictory evidence (Tetlock, 1983, 1985). This relative open-mindedness will manifest itself in a variety of cognitive tasks and interpersonal settings. Integratively complex persons will (a) actively seek out information about the world, (b) be open to new experiences and unusual forms of art, (c) be good listeners even to points of view they find distasteful, (d) identify more creative integrative solutions to problems, (e) tend to hold balanced, nuanced, and moderate positions in political controversies, (f) appear less predictable and stable in behavior (it is hard to anticipate which attitude or combination of attitudes will guide their responses), (g) be cognitively self-directed (the mere fact that other people are doing something, or that an authoritative person says to do it, is not a good enough reason for the integratively complex to do it; as a result, they display greater independence of judgment when social pressures toward conformity or groupthink are brought to bear on them; cf. Harvey, Hunt, \& Schroder, 1961; Schroder et al., 1967; Streufert \& Streufert, 1978; Tetlock, 1979, 1983, 1984; Tetlock \& Kim, 1987).

By contrast, the flattering portrait of integratively simple thinkers depicts them as practical, decisive, and principled. 
These individuals recognize the usefulness of simple rules of thumb in life. In many situations, there is little to be gained and potentially a lot to be lost from obsessing over the pros and cons of various options (Suedfeld \& Tetlock, 1991). Simple thinkers recognize more quickly than their complex counterparts when they have reached the point of diminishing returns for further thought about an issue. Simple thinkers are also less likely to agonize over decisions because they are more likely to believe they have discovered a "dominant" option that does not require trade-offs and is superior to the alternatives on all criteria that matter. As a result, simple thinkers should appear more calm, relaxed, and confident (cf. Streufert \& Swezey, 1986). Finally, simple thinkers recognize the importance of being good team players who accept (rather than continually question) the basic purposes and ground rules of the collectivities to which they belong. Loyalty to the group, a cooperative attitude toward fellow group members, and the conscientious observance of group norms and performance of group tasks are important virtues.

The unflattering portrait of integratively simple thinkers emphasizes both their willingness to jump to conclusions and unwillingness to change their minds-a combination of cognitive impulsivity and rigidity. This relative closed-mindedness is expressed in many ways, including (a) excessive confidence in one's point of view, (b) contempt for other points of view, (c) a dislike for novel, asymmetric, and complex aesthetic stimuli, (d) a reliance on broad-brush generalizations and stereotypes, (e) a failure to appreciate nuances, shades of gray, and subtleties, (f) a tendency to take extreme and affectively polarized political positions, ${ }^{1}$ and (g) susceptibility to extreme in-group loyalty (which can take the form of fanaticism and prejudice toward out-groups) and authoritarianism (which can take the form of bullying subordinates and sycophantic fawning over high-status members of the in-group).

The unflattering portrait of integratively complex thinkers depicts them as excessively intellectual, impractical, and indecisive. It is possible to be too sensitive to trade-offs and counterarguments, so sensitive that one either is effectively paralyzed (Tetlock, 1992, reported that complex thinkers tended to be buckpassers and procrastinators in difficult cost-benefit decisions) or experiences excessive anxiety and arousal (as Streufert \& Swezey, 1986, reported in their studies of managers). Integratively complex thinkers may also be more easily misled. Tetlock and Boettger (1989) showed that complex thinkers were especially likely to seek relevance in irrelevant information and to "dilute" confident predictions when diagnostic cues were embedded in arrays of nondiagnostic evidence. It is also possible to be too skeptical of others and too prone to take the devil's advocate role-a stance that will annoy fellow group members who seek agreement and interpersonal harmony. Integratively complex thinkers may so highly value their cognitive autonomy (freedom to entertain unconventional and deviant ideas) that they frequently rub people the wrong way: as confused, wishywashy and vacillating on the one hand or as self-absorbed, contentious, and uncooperative on the other hand.

The present study allows us to assess the relative validity of these competing portraits of integrative simplicity and complexity by drawing on data collected during in-depth, 3-day assessments of master of business administration (MBA) candidates conducted at the Institute of Personality and Social Re- search (IPSR), Berkeley, California. We assessed the integrative complexity of the MBA students by systematically coding their open-ended responses to the semiprojective Picture Story Exercises (PSE), a form of the Thematic Apperception Test (Murray, 1938) discussed in detail by Boyatzis (1982). We then analyzed the relationship of this measure of integrative complexity with a broad range of self-report, observer rating, managerial simulations, and semiprojective measures of personality obtained in these joint managerial-personality assessments.

\section{Method}

\section{Subjects}

The subjects were 131 ( 77 men and 54 women) MBA students who volunteered to participate in a weekend-long assessment program at IPSR. ${ }^{2}$ The average age of the sample was 27.7 years (range 21-41 years), and the average number of years of postsecondary education completed at the time of participation was 4.9 .

\section{Assessors}

Two groups of assessors participated in the study-personality and managerial assessors. Neither research team expected that the data they generated would be used to test competing hypotheses concerning the personality correlates of integrative complexity (nor were they aware of the integrative complexity scores of the MBA "assessees," thus satisfying the requirements of a double-blind design). The personality assessors were faculty members, research staff, postdoctoral fellows, and advanced graduate students trained in personality assessment. The number of personality judges per weekend ranged from 10 to 12 , depending on the number of assessees recruited for each weekend. There were approximately even numbers of male and female judges in each group.

The managerial assessors were business school faculty members, personality faculty, and advanced graduate students trained in methods of managerial assessment. Two teams of three managerial assessors participated per weekend, with approximately equal numbers of men and women on each team.

\footnotetext{
"We list the tendency to be politically moderate as a "flattering" attribute of the complex and the tendency to be politically extreme as an "unflattering" attribute of the simple. Such a judgment call is obviously value laden and can be easily reversed. Integratively simple thinkers, for example, were overrepresented among extreme opponents and proponents of slavery in pre-Civil War America, and the integratively complex were overrepresented among the centrists (Free-Soil Republicans and Buchanan Democrats), who sought compromise solutions that would preserve the union, avoid war, and permit slavery in many states (Tetlock, Armor, \& Peterson, 1992).

${ }^{2}$ MBA students are obviously not a representative cross-section of the general population, but their scores on personality measures do not vary much from the norms. Means on the CPI and the ACL scales in our sample are all within one standard deviation of norms for representative samples of adults. Using the MBA student assessees gave us the opportunity to explore correlates of cognitive style across an unusually broad range of measures. The MBA student sample is also likely to be of long-term interest to personality and life-span developmental psychologists. Researchers at Berkeley have recently planned a series of longitudinal studies of the MBA students that will allow us to measure the power of individual-difference measures obtained in early adulthood to predict both career and family success.
} 


\section{Materials}

The test materials (and data) may be divided into four broad categories: (a) self-report personality inventories (also known as $\mathrm{S}$-data or respondent measures), (b) observer data ( $\mathrm{O}$-data; based on observations of subjects by trained personality judges), (c) projective or operant measures, and (d) simulation data. ${ }^{3}$ The self-report data included traditional inventories (e.g., the California Psychological Inventory, CPI, and the Myers-Briggs Type Indicator, MBTI) as well as personality and managerial questionnaires developed specifically for this assessment program (e.g., a personality trait rating form and a managerial dimensions rating form).

Two types of $\mathrm{O}$-data were obtained from staff trained as personality or managerial assessors. The personality assessors rated subjects on a broad range of individual differences, using both standardized (e.g., the Adjective Check List, ACL, and the California Adult Q-Set, CAQ) and IPSR-based questionnaires (e.g., a trait-rating form). The managerial assessors focused only on managerial performance in the business simulations (e.g., the In-Basket Simulation Exercise, IBE).

Assessees completed one multiple-item projective measure--the PSE. We assessed both motivational imagery (need for affiliation, achievement, and power) and integrative complexity from these protocols.

Subjects also completed four simulation exercises that required enacting various roles. Three of the exercises involved role playing in groups observed by the assessors, whereas the fourth was the IBE, a 3-hour procedure during which subjects assumed the role of a newly appointed manager of a large computer microchip manufacturing company. The task is to respond to 21 "in-basket" memoranda that demand immediate attention. Six scales are scored from the subjects' hand-written responses: delegation, written communication, planning and organizing, analysis, judgment, and control.

\section{Procedure}

IPSR assessments are labor-intensive, time-consuming procedures. The first phase includes a battery of 34 self-report measures completed in three different sessions: (a) an initial 3-hr group testing session held 2 weeks before the weekend assessment, (b) a take-home packet mailed to subjects 1 week before the assessment weekend, and (c) a group-testing session of timed procedures conducted on the first evening (Day 1 procedures) of the assessment. All 131 subjects completed this portion of the assessment. Of this group, 94 were subsequently observed and assessed during weekend-long sessions from which additional data were obtained in the form of judges' observations of the subjects across a variety of settings, including (a) social events, (b) leaderless group discussions, (c) structured games, (d) a managerial simulation task, and (e) a life-history interview. Subjects who completed the full assessment were "under the microscope" for an entire weekend.

Thus, only S-data are available for a subset of 37 subjects, whereas both $\mathrm{S}$-data and O-data are available on the subset of 94 assessees who attended the weekend assessment. The subset of 94 assessees participated in groups of 10,11 , or 12 persons and were assessed during one of eight weekends in 1986 and 1987.

\section{Managerial Staff}

Two teams of three judges each comprised the managerial staff; one team member served as the leader of the group. Each team assessed six subjects. There were three sources of information on which judges based their ratings, and each judge was responsible for observing two different subjects in each of the three settings. The three sources were the IBE task completed individually by subjects, the Work and Professional Field Interview (WPFI), and the Leaderless Group Discussion (LGD).

Day 1 procedures. In the evening, subjects completed all timed tests and attended an evening social event where personality observers began their interactions with the assessees.

Day 2 procedures. In the morning, each subject completed the 3hour IBE followed by a group luncheon with the other assessees and the personality assessors. In the afternoon, each of the six managerial judges conducted two 1 -hour individual work and professional field interviews. In the evening, the managerial observers scored the IBE materials for two preassigned subjects and wrote two career sketches based on the WPFIs conducted that afternoon.

Day 3 procedures. Each team observed one of two LGDs; the LGD is a 1-hour procedure with 6 assessees who are assigned (as a group) the task of allocating scarce organizational resources to competing claimants (each of whom is represented by a group member). Each team member also observed the two assessees with whom she or he had not already become familiar, either through conducting their WPFI or scoring their IBE materials. Behaviors indicative of managerial style and leadership were recorded for these two preassigned assessees.

The managerial teams met separately on Day 3 for lunch and an afternoon of discussion to rate the six assessees for whom they were responsible. The meetings proceeded case by case (i.e., subject by subject). Each judge presented to the other group members the information for which she or he was responsible: the LGD observations, the WPFI (i.e., career portrait and interesting details from the interview), or the IBE performance. The judges then privately rated the subjects on 15 managerial dimensions and arrived at consensus using a rule of at least two identical ratings on a 5-point rating scale. If two identical ratings were not yielded from the individual ratings, the group discussed why not and arrived at a consensus rating. This procedure was followed for all six subjects in each group.

\section{Personality Staff}

The objective for the managerial raters was to assess participants and make predictions about each participant's likely success in a managerial position. Managerial assessors specifically avoided contact with participants outside the scheduled tasks. In contrast, the personality staff observed the subjects in informal social gatherings, including a Day 1 evening social and dessert hour before the timed tests, continental breakfasts and lunches on Days 2 and 3, and a social hour and debriefing session conducted at the close of the assessment on Day 3. The staff were instructed to get to know all 12 of the assessees in this variety of social settings. On the morning of Day 2, while the subjects completed the IBE (between 9 a.m. and 12 noon), the personality judges were briefed by the assessment staff on the rating procedures. In the afternoon each judge interviewed 1 subject for $1.5 \mathrm{hr}$ (the Life History Interview). On the morning of Day 3, all 12 judges observed all 12 subjects in both the LGDs, focusing on personality characteristics that emerged during this procedure. On Day 3, all 12 judges observed four groups of 3 subjects each performing the Role Improvisation task. The final task was a charades game consisting of two teams of 6 subjects each; all 12 judges observed the subjects performing charades. Separate rating forms were completed by the judges at the end of each procedure. During the final evening, each judge completed the CAQ for 5 preassigned subjects, completed an ACL for each of the 12 subjects, rated all 12 on 28 personality traits, and wrote a character sketch for the individual she or he interviewed the previous afternoon. (Note: lunch seating assignments on Days 2 and 3 were carefully designed to maximize social interaction between judges and the 5 subjects whom they assessed on the CAQ.)

\footnotetext{
${ }^{3}$ A complete description of the entire set of procedures and tests performed by subjects is available on request. Only those tests most relevant to the present study are reported here.
} 


\section{Assessment of Integrative Complexity}

The coding procedures for assessing integrative complexity were originally developed by Schroder et al. (1967) and subsequently clarified and expanded by Suedfeld (1983), Tetlock (1983, 1986), and most recently in a collaborative manual authored by researchers at the University of British Columbia and at the University of California, Berkeley (Baker-Brown, Ballard, Bluck, deVries, Suedfeld, \& Tetlock, 1992). Integrative complexity is defined in terms of two cognitive stylistic variables: evaluative differentiation and conceptual integration. Evaluative differentiation refers to the capacity and willingness to tolerate conflicting interpretations of the same event. An evaluatively undifferentiated thinker tends to dichotomize events, options, and people into airtight, good-bad categories that admit no exceptions. An evaluatively differentiated thinker allows for the possibility that inconsistencies and contradictions are a common and indeed inevitable feature of social life. Bad consequences can flow from good intentions, good consequences can flow from bad intentions, most decisions require weighing competing values, and most people are complex mixtures of both positive and negative traits.

Integration refers to the development of conceptual connections among evaluatively differentiated cognitions. One common type of integration is the systematic effort to explain why reasonable people view the same event in different ways. A second type of integration involves recognition of interactive causality (the effects of $A$ on $B$ depend on levels of $C$ ). A third type of integration involves the recognition of value trade-offs (how much of value $x$ am I prepared to give up to achieve this much of value $y$ ?).

The assessment of integrative complexity proceeds on a 1-7 scale in which scores of 1 signify low levels of both differentiation and integration, scores of 3 signify the presence of differentiation but the absence of any integration, scores of 5 indicate the presence of both differentiation and conceptual integration, and scores of 7 indicate differentiation plus the specification of higher order integrative principles.

Two trained integrative complexity coders independently assigned complexity ratings to each of six responses to semiprojective pictorial stimuli used in the PSE. The stimuli included a picture of a man and woman sitting together at a table in a restaurant, a picture of a worker at his desk, a picture of a man and woman at a park bench looking out onto a river, a picture of two female scientists at work in a laboratory, a picture of a male ship's officer speaking to someone else not in uniform, and a picture of a female gymnast performing before an audience. Integrative complexity scores were averaged across the six stories to yield a single measure of integrative complexity. The correlations of integrative complexity scores across pictures ranged from .18 to .40 , with a Cronbach alpha of 71 . The judgments of the two integrative complexity coders correlated at 88 .

Below we provide prototypical examples of PSE responses that received scores of $1,3,5$, and 7 .

The following response to a PSE stimulus illustrates a prototypical 1:

My two characters' names are Karen and Kevin. They have gone out for the evening to talk about their future plans. Unfortunately, the bar is noisy and they can't seem to get rid of this guy playing the guitar. Karen is agitated about the state of the relationship. She feels unloved; she feels neglected. She is going to give Kevin an ultimatum. Either Kevin must make a solid commitment to marriage and children, or Karen will leave him.

The subject took into account only one point of view (that of Karen) in analyzing what was happening in the picture. The subject also dichotomized potential outcomes. In the fictional figure's mind, there was a clear right and a clear wrong way to proceed (either commitment or dissolution of the relationship).

The next response illustrates a prototypical 3:

This is a story about Karl, who is an engineer from United Technologies. Karl has worked here for over 20 years, as he is a good, steady worker. Lately, Karl has felt torn. He loves his wife and children, and he enjoys spending time with them. However, Karl has just received a promotion and has had to make a big commitment of time to a large project. He enjoys his job, and he needs the money. He's not sure what is going to happen now. His wife already resented the amount of time he spent at work. He is worried.

This response shows evidence of differentiation but no evidence of integration. The response recognizes the tension between two major objectives of Karl: a happy family life and a successful career. The response also takes into account the point of view of another individual (namely Karl's wife). The response does not, however, provide any indication as to how Karl might reconcile the tension between these two important objectives in his life. The absence of any even implicit integration justifies assigning a score no higher than 3 .

The next example is a prototypical 5:

Two men are talking. One wears a hat as in the uniform of a sailor. From the uniform we can tell he is a high-ranking officer of the ship. The other man is a passenger. The ship's officer is explaining to the passenger that the customs officials insist on searching all passengers and their possessions. The passenger is formally dressed up and appears to be offended. ... The officer feels stuck between conflicting demands. He wants to keep his passengers happy, but he also has to obey the laws of the land. He tells the passenger that he will try to minimize the inconvenience, but there is a limit to what he can do. He asks the passenger to see the situation from his point of view. It is impossible to satisfy everybody. His job is to strike reasonable balances between unreasonable people.

This response not only differentiated between the points of view of the passenger and the ship's officer, but also specified a strategy for mediating between these conflicting perspectives and interests. The reference to striking balances is a particularly clear-cut integrative cognition.

Scores of 7 occur sufficiently rarely that it is inappropriate to call any example prototypical. The following response, however, illustrates higher-order integration:

There are two women. The one with glasses looks older, and the other one is performing some kind of experiment. The experiment is intended to distinguish between two theories of how viruses replicate themselves. Each woman believes in a different theory. But neither theory explains the data. The women are at turning points in their careers. Their first reaction is to think that the methods must have been flawed. So they have redone the experiment several times. Slowly, they realize the need for a more general theory that treats their original theories as special cases. The question is whether they are emotionally and intellectually up to the challenge. They never liked each other very much. And it is hard to admit that one was wrong. It is also not easy to come up with a theory that explains all this contradictory data. But the stakes are high. Reputations, lives, and Nobel Prizes hang in the balance.

This response shows evidence of both differentiation (the different theoretical points of view on viral reproduction of the two scientists) and integration (it recognizes the difficulty that the two women have in revising their theories in response to new evidence and in fashioning a more general integrative formulation). Finally the response shows evidence of second-order integration (a variety of factors-some petty, some not-determine the difficulty of creating that integrative formulation).

\section{Motive Imagery Coding}

Measures of affiliation, power, and achievement were derived from coding performed by the trained and carefully monitored analysts at McBer and Company. These professional coders are tested periodi- 
cally against expert coding for power, achievement, and affiliation and must maintain at least $85 \%$ agreement with the experts. Coding procedures were based on those described in McClelland (1961), Winter (1973), and Atkinson (1958). High scorers for need power exhibit a concern with influence over others and with having an impact on the world (e.g., impressing others, helping them, bullying them, and persuading them). High scorers for need affiliation seek to engage others, to be close to them, to share information, and to enjoy their company. High scorers for need achievement are concerned with long-term involvement, competition against standards of excellence, and unique accomplishments (McClelland, 1958).

\section{Results}

\section{Descriptive Statistics of Integrative Complexity Measure}

The average integrative complexity scores of assessees ranged from 1.0 to $4.0(M=2.2, S D=.81)$. The absolute level and variation in scores are quite consistent with results of other laboratory and archival studies of integrative complexity (Tetlock, 1989). We should also emphasize that the results reported here cannot be attributed to shared variance between integrative complexity and intellectual ability (a common problem in studies of cognitive style). Integrative complexity was not signifcantly correlated with verbal or quantitative scores on the Graduate Management Admission Test $(r \mathrm{~s}=.08$ and .10 , respectively), an aptitude test that, like most such tests, correlates highly with traditional ability measures. ${ }^{4,5}$

\section{S-data}

Self-report measures completed by the subjects included ${ }^{6}$ (a) the MBTI (Myers \& McCaulley, 1985), (b) the ACL (Gough \& Heilbrun, 1983), (c) the CPI (Gough, 1987), (d) the Participant Ratings of Managerial Dimensions in General and the Managerial Dimensions Ratings for the Assessment Weekend (MDRG and MDRW; IPSR measures), (e) the Work Environment Preference questionnaire (WEP; IPSR measure), (f) the Vocational Preference Inventory (VPI; Holland, 1978), (g) the Trait Ratings of Self (TR-S; IPSR measure), (h) the Managerial Composite Personality Inventory (MCPI; IPSR measure), and a number of other self-report scales. We report all significant correlations ( $p<.05$, two-tailed) with integrative complexity in Table 1.

These correlates show that the integratively complex see themselves as creative and independent people who are openminded and empathic. The MBTI scales for Intuition (N) and Perceiving $(\mathrm{P})$ yielded the largest correlations. These findings are consistent with the intended applications of the two scales to assess imaginative and intuitive psychological functioning $\mathrm{N}$ ) and with an open-minded willingness to suspend judgment and consider alternatives (P). The strongest $\mathrm{ACL}$ correlations were with the Creative Personality and the Free Child scales. The CPI showed a number of significant correlations, including a positive relationship with Creativity and Independence and a negative relationship with the Achievement via Conformity scale. And, in contrast with the personality observer data to be discussed later, integratively complex individuals saw themselves as empathic. The MDRW indicated that the integratively complex individuals rated themselves as less sensitive to others during the weekend assessments (even though they believe they are generally empathic as indicated by the CPI) and less skilled in written communications. The WEP showed a strong relationship between integrative complexity and the desire to have a work environment that pressured them to produce; they indicated that they enjoyed challenging tasks. They did not, however, want a work environment that tied work performance tightly to rewards or employers who used strong work motivations (e.g., threats of firings or lay-offs, large pay differentials between most and least preferred workers). The VPI yielded a number of correlates that are consistent with the integratively complex individual's self-perception as creative and nonconforming. Specifically, the artistic scale was correlated positively $(r=.25)$ and the conventional scale was correlated negatively $(r$ $=-.28)$ with integrative complexity. ${ }^{7}$ The TR-S correlations indicated that the complex individuals rated themselves relatively low on orderliness and responsibility $(r s=-.31$ and -.28 , respectively) and marginally less involved in the assessment itself $(r=-.17, p<.07)$. The MCPI yielded results similar to those already reported, including high overall empathy $(r=.20)$, independence $(r=.19)$, and low acquiescence $(r=-.24)$. In addition, the MCPI yielded a significant positive correlation for Gough's (1956) Cognitive Flexibility scale, indicating the ability to shift and adapt and to deal with the unexpected. Finally, a number of individual self-report scale correlations suggested that both creativity and originality (Revised Art Scale $r=.25$ and Barron-Welsh Art Scale $r=.22$; Barron \& Welsh, 1960) were positively related to integrative complexity.

\section{Personality O-data}

Personality observer data provided a quite different perspective on the integratively complex individual than did the self-re-

\footnotetext{
${ }^{4}$ The null result is not surprising. Integrative complexity and mental ability are usually uncorrelated in samples in which the mean level of intelligence exceeds the general population average by at least one standard deviation (cf. Schroder, Driver, \& Streufert, 1967). Intelligence is best thought of as a necessary, but not sufficient, condition for the emergence of integratively complex reasoning.

${ }^{5}$ Sex differences were not pronounced in this study. Integrative complexity is not significantly correlated with sex of subject $(r=.10, p=$ .14), and the correlates of integrative complexity for men and women separately are generally similar, with the following four exceptions: Hogan Empathy $r=.39$ for women and $r=-.0002$ for men; Assessment Involvement $r=-.36$ for women and $r=.009$ for men; CAQ (Item 1) Critical/Skeptical $r=.44$ for women and $r=.12$ for men; and CAQ (Item 35) Warmth/Compassion $r=-.43$ for women and $r=-.05$ for men. This pattern of correlates indicates that although both the integratively complex men and women were characterized in a similarly negative fashion by personality observers, the women were judged even more harshly than the men.

${ }^{6}$ Although means and ranges are not given for the measures reported here, it is important to note that results for all tests were within normal population parameters (means are within one standard deviation, and standard deviations for this sample are nearly identical to those of representative samples of adults).

${ }^{7}$ These are actually partial correlations examined after controlling for a positive correlation $(r=.23)$ between integrative complexity and VPI Acquiescence, a response bias scale designed to detect a tendency toward "yea-saying." In the factor analysis, however, only the VPI Artistic scale was entered because it was the only VPI scale that met the criteria for inclusion in the principal-components analysis (i.e., zeroorder correlation $>.25$ ).
} 
Table 1

Correlations of Integrative Complexity With Self-Report Measures

\begin{tabular}{|c|c|c|c|c|c|c|}
\hline \multirow[b]{2}{*}{ Scale } & \multicolumn{3}{|l|}{ Positive } & \multicolumn{3}{|l|}{ Negative } \\
\hline & Item & $r$ & $p$ & Item & $r$ & $p$ \\
\hline MBTI & $\begin{array}{l}\text { Intuition } \\
\text { Perception }\end{array}$ & $\begin{array}{l}.41 \\
.56\end{array}$ & $\begin{array}{l}.001 \\
.001\end{array}$ & & & \\
\hline $\mathrm{ACL}$ & $\begin{array}{l}\text { Creative Personality } \\
\text { Free Child }\end{array}$ & $\begin{array}{l}.27 \\
.20\end{array}$ & $\begin{array}{l}.004 \\
.04\end{array}$ & & & \\
\hline $\mathrm{CPI}$ & $\begin{array}{l}\text { Creativity } \\
\text { Independence } \\
\text { Flexibility } \\
\text { Empathy }\end{array}$ & $\begin{array}{l}.27 \\
.21 \\
.19 \\
.19\end{array}$ & $\begin{array}{l}.004 \\
.03 \\
.04 \\
.04\end{array}$ & $\begin{array}{l}\text { Achievement via conformity } \\
\text { Self-control } \\
\text { Work orientation } \\
\text { Good impression } \\
\text { Socialization }\end{array}$ & $\begin{array}{l}-.39 \\
-.32 \\
-.21 \\
-.20 \\
-.19\end{array}$ & $\begin{array}{l}.001 \\
.001 \\
.01 \\
.02 \\
.04\end{array}$ \\
\hline MDRW & & & & $\begin{array}{l}\text { Sensitivity to others } \\
\text { Written communications }\end{array}$ & $\begin{array}{l}-.25 \\
-.22\end{array}$ & $\begin{array}{l}.01 \\
.02\end{array}$ \\
\hline WEP & Pressure to produce & .28 & .003 & $\begin{array}{l}\text { Performance-reward relation } \\
\text { Employee work motivation }\end{array}$ & $\begin{array}{l}-.24 \\
-.21\end{array}$ & $\begin{array}{l}.01 \\
.02\end{array}$ \\
\hline VPI & $\begin{array}{l}\text { Artistic } \\
\text { Acquiescence }\end{array}$ & $\begin{array}{l}.25 \\
.23\end{array}$ & $\begin{array}{l}.01 \\
.01\end{array}$ & Conventional & -.28 & .003 \\
\hline TR-S & & & & $\begin{array}{l}\text { Orderliness } \\
\text { Responsibility } \\
\text { Social compliance }\end{array}$ & $\begin{array}{l}-.31 \\
-.28 \\
-.24\end{array}$ & $\begin{array}{l}.001 \\
.003 \\
.009\end{array}$ \\
\hline MCPI & $\begin{array}{l}\text { Barron complexity } \\
\text { Gough cognitive flexibility } \\
\text { Hogan empathy } \\
\text { Barron originality } \\
\text { Barron independence }\end{array}$ & $\begin{array}{l}.30 \\
.22 \\
.20 \\
.19 \\
.19\end{array}$ & $\begin{array}{l}.002 \\
.02 \\
.04 \\
.05 \\
.05\end{array}$ & $\begin{array}{l}\text { Barron soundness } \\
\text { Kamp social acquiescence }\end{array}$ & $\begin{array}{l}-.26 \\
-.24\end{array}$ & $\begin{array}{l}.005 \\
.01\end{array}$ \\
\hline $\begin{array}{l}\text { Revised } \\
\text { Barron- }\end{array}$ & $\begin{array}{l}\text { Scale } \\
\text { Ish Art Scale }\end{array}$ & $\begin{array}{l}.25 \\
.22\end{array}$ & $\begin{array}{l}.007 \\
.02\end{array}$ & & & \\
\hline
\end{tabular}

Note. $\quad$ MBTI $=$ Myers-Briggs Type Indicator $; \mathrm{ACL}=$ Adjective Check List-Self; $\mathrm{CPI}=$ California Psychological Inventory; MDRW = Managerial Dimensions Rating for Assessment Weekend; WEP = Work Environment Preference Questionnaire; VPI $=$ Vocational Preference Inventory; TR-S $=$ Trait Ratings-Self; MCPI = Managerial Composite Personality Inventory.

port data. The information generated by the personality assessors included (a) the CAQ (average Cronbach alpha across subjects $=.76)$, (b) the Staff Adjective Check List (STACL; Gough \& Heilbrun, 1983), (c) Trait Ratings for Observers (TR-O; IPSR measure; average Cronbach alpha $=.86$ ), and (d) the LGD (average Cronbach alpha $=.69$ ). Table 2 reports all significant correlates with integrative complexity.

Of the 100 items included in the CAQ, 18 correlated significantly with integrative complexity: 12 positively and 6 negatively. As Table 2 reveals, personality observers judge the integratively complex to be inconsiderate and undependable (e.g., negative correlations with "behaves in a giving way toward others"; "behaves in a sympathetic and/or considerate manner"; and "is a genuinely dependable and responsible person"), skeptical (e.g., positive correlations with "is critical, skeptical, not easily impressed"), labile in mood and action (e.g., "is unpredictable and changeable in behavior and attitudes"), domineering and hostile (e.g., positive correlations with "exploits others" and "expresses hostility"), and self-absorbed, even narcissistic (e.g., positive correlation with "tries to stretch limits" and "unable to delay gratification").

The $A C L$ ratings present a psychological profile consistent with the CAQ results. They reveal the integratively complex
MBA student to be an interpersonally cold and intellectually critical individual. The 16 negatively correlated items include reliable, civilized, conscientious, and considerate. The 23 positively correlated items include rebellious, resentful, vindictive, and individualistic.

The trait ratings by observers yielded one marginally significant correlation: an inverse relationship between integrative complexity and social compliance $(r=-.20, p<.06)$.

The LGD had one item that was significantly correlated with integrative complexity. Criticality was positively related $(r=.20)$ to integrative complexity. These correlates are again consistent with the other personality assessor observations.

\section{Managerial O-data}

In contrast with the generally negative tone of the personality observer assessments, the Managerial Dimensions Rating Consensus (MDRCON) of all observers' ratings (average Cronbach alpha $=.80$ ) of the integratively complex (based on the consensus of all managerial raters) included two items that correlated significantly with integrative complexity-initiative and selfobjectivity $(r \mathrm{~s}=.22$ and $.21, p<.02$, respectively) - and two that were marginally significant-written communications and 
Table 2

Correlations of Integrative Complexity With Personality Observer Measures

\begin{tabular}{|c|c|c|c|c|c|c|}
\hline \multirow[b]{2}{*}{ Scale } & \multicolumn{3}{|l|}{ Positive } & \multicolumn{3}{|l|}{ Negative } \\
\hline & Item & $r$ & $p$ & Item & $r$ & $p$ \\
\hline \multirow[t]{12}{*}{ CAQ } & Unpredictable & .28 & .006 & Dependable/responsible & -.29 & .004 \\
\hline & Exploits others & .27 & .009 & Sympathetic/considerate & -.29 & .005 \\
\hline & Critical/skeptical & .26 & .01 & Is fastidious & -.24 & .01 \\
\hline & Expresses hostility directly & .26 & .01 & Giving toward others & -.24 & .02 \\
\hline & Tries to stretch limits & .25 & .01 & Warmth/compassion & -.21 & .05 \\
\hline & Expresses hostility & .24 & .01 & Others like/accept & -.21 & .05 \\
\hline & Extrapunitive & .24 & .02 & & & \\
\hline & Reactive to frustration & .23 & .02 & & & \\
\hline & Subtly negativistic & .23 & .03 & & & \\
\hline & Rebellious & .23 & .03 & & & \\
\hline & Distrustful of others & .22 & .03 & & & \\
\hline & Unable to delay gratification & .21 & .05 & & & \\
\hline \multirow[t]{23}{*}{ STACL } & Rebellious & .34 & .001 & Reliable & -.31 & .002 \\
\hline & Resentful & .33 & .001 & Civilized & -.29 & .005 \\
\hline & Courageous & .31 & .003 & Deliberate & -.29 & .005 \\
\hline & Selfish & .31 & .002 & Reasonable & -.29 & .004 \\
\hline & Spendthrift & .28 & .007 & Suggestible & -.25 & .01 \\
\hline & Bitter & .27 & .009 & Dependable & -.24 & .02 \\
\hline & Individualistic & .26 & .01 & Conscientious & -.23 & .03 \\
\hline & Daring & .25 & .01 & Discreet & -.23 & .03 \\
\hline & Vindictive & .25 & .02 & Cautious & -.22 & .04 \\
\hline & Zany & .25 & .01 & Considerate & -.22 & .04 \\
\hline & Irresponsible & .24 & .02 & Moderate & -.21 & .04 \\
\hline & Original & .24 & .02 & Peaceable & -.21 & .04 \\
\hline & Tough & .24 & .02 & Kind & -.20 & .05 \\
\hline & Undependable & .24 & .02 & Conservative & -.20 & .05 \\
\hline & Adventurous & .23 & .03 & Pleasant & -.20 & .05 \\
\hline & Unkind & .23 & .03 & Prudish & -.20 & .05 \\
\hline & Bossy & .22 & .03 & & & \\
\hline & Irritable & .22 & .03 & & & \\
\hline & Reckless & .22 & .03 & & & \\
\hline & Emotional & .21 & .05 & & & \\
\hline & Clever & .20 & .05 & & & \\
\hline & Immature & .20 & .05 & & & \\
\hline & Opportunistic & .20 & .05 & & & \\
\hline LGD & Criticality & .20 & .05 & & & \\
\hline
\end{tabular}

Note. $\mathrm{CAQ}=$ California Adult $\mathrm{Q}-$ Set; $\mathrm{STACL}=$ Staff Adjective Check List; $\mathrm{LGD}=$ leaderless group discussion.

written fact finding $(r=.18, p<.06$, and $r=.15, p<.10$, respectively). These correlates portray the integratively complex person as a self-starter who can be objective about herself or himself. (These data were based on observation during simulation activities only)

\section{Semiprojective Data}

Integrative complexity and motivational imagery were both scored from subjects' responses to the semiprojective PSE. Of the three motives assessed (affiliation, achievement, and power), only one-need power-was significantly correlated with integrative complexity $(r=.30, p<.001){ }^{8}$

\section{Principal-Components Analysis}

To organize the multitude of zero-order correlations into an integrative framework, we conducted an exploratory principalcomponents analysis on the 37 items that correlated beyond
|.25| with integrative complexity. This item selection procedure yielded a 2.5:1 subject-to-variable ratio. Examination of the eigenvalues (reported in Table 3) indicated that a four-factor solution best characterizes these data (each of the four components

\footnotetext{
${ }^{8}$ We computed partial correlations between integrative complexity and the four-factor scores (controlling for need power) to explore the possibility that need power partly or fully "explained" the links between integrative complexity and factor scores (e.g., did observers form certain impressions of integratively complex MBA students partly or wholly because complex MBA students tended to be higher in need power?). The results revealed that the self-report and observer-rating correlates of integrative simplicity-complexity are not incidental byproducts of the tendency of integratively complex MBA students to score higher in need power. Only the correlation between integrative complexity and Factor II, Surgency/Ego Control, fell to nonsignificance $(r=.17, p<.11)$. It appears, then, that integrative complexity is uniquely related to Factors I, III, and IV even when shared variance with need power is explained.
} 
Table 3

Eigenvalues of Factor Scores (Varimax Rotation)

\begin{tabular}{ccc} 
Factor & Eigenvalue & Percentage of variance \\
\hline I & 10.8 & 29.1 \\
II & 3.1 & 8.3 \\
III & 2.7 & 7.3 \\
IV & 2.2 & 6.0 \\
\hline
\end{tabular}

in this solution consist of seven or more correlates). The results are reported in Table 4 . Three of the four factors correspond roughly to three of the Big Five dimensions of personality (John, 1990). Factor I is negative Agreeableness (henceforth called Disagreeableness), Factor III is Openness to Experience, and Factor IV is Conscientiousness. The interpretation of Factor II is less clear, but appears to capture negative aspects of Surgency (Big Five Factor I) and Ego Control (Block \& Block, 1980). Specifically, Factor II includes characteristics such as zany, rebellious, and daring, suggesting an individual who is somewhat flamboyant and undercontrolled (does not censor emotional expressions).

From the principal-components analysis, composite factor scores were created and then correlated with integrative complexity. Factor I, the Disagreeableness factor, correlated positively $(r=.21, p<.04)$ with integrative complexity. This factor consists entirely of the personality observer assessments that depicted the integratively complex individuals as contentious and disagreeable (e.g., hostile, unreasonable, and vindictive). Factor II, the Surgency/Ego Control (lack of emotional censorship) factor correlated positively $(r=.20, p<.05)$ with complexity. Factor III, the Openness to Experience factor, correlated positively $(r=.34, p<.001)$ with integrative complexity. Finally, Factor IV, the Conscientiousness factor, correlated negatively $(r$ $=-.43, p<.001$ ) with integrative complexity.

\section{Correlations With CAQ Theoretical Prototypes}

Convergent evidence for the results obtained in the principalcomponents analysis was obtained in an analysis of several theoretical prototypes derived from the $C A Q$. The $Q$-sort ratings of the MBAs were correlated with CAQ-derived prototypes of theoretical psychological constructs. These correlations serve as scores indicating the degree to which individuals are prototypical of a particular construct. These prototype scores were then correlated with integrative complexity. Positively correlated prototypes included Stanford Narcissism $(r=.27, p<.01)$ and Wink Narcissism $(r=.25, p<.01)$. The negatively correlated prototypes included Warmth $(r=-.27, p<.01)$ and Conscientiousness $(r=-.25, p<.01)$. The correlations between integrative complexity and Surgency $(r=.09)$ and Undercontrolled $(r=.16)$ were positive, but failed to reach statistical significance.

\section{Discussion}

Peabody (1967) argued that personality descriptions involve complex mixtures of denotative and connotative meaning. The terms we use to describe others, in part, reflect reality and, in part, reflect our evaluations of reality. To describe someone as cautious is to make a statement about that person's tolerance for risk as well as a statement about what we regard as reasonable risk aversion (the person is neither timid nor rash). The portraits of the integratively simple and complex MBA students that emerge from this study should be viewed in this light. Although there are underlying behavioral, cognitive, and motivational factors that distinguish integratively simple from complex assessees, there is no value-neutral language for capturing these differences. It is possible to draw on our data to construct both flattering and unflattering portraits of integratively simple and complex people. Advocates of each of the four portraits sketched earlier can seize on certain aspects of the data to support their position. ${ }^{9}$

The most flattering (empirically sustainable) portrait of integratively complex MBA students depicts them as independent, creative, open to new and different experiences, and intuitive in the MBTI sense, that is, able to bring disparate ideas together into meaningful wholes. There is, however, an interpersonal price to be paid for self-assertive open-mindedness. The unflattering portrait of integratively complex individuals shows them as narcissistic, hostile, exploitative of weaknesses in others, and even power hungry. These individuals were apparently not popular among the personality assessment staff. Interestingly, the Disagreeableness factor, on which integratively complex assessees scored high, was composed entirely of items based on personality staff observations.

Moreover, the more integratively complex individuals may have reciprocated the feeling. They scored marginally lower on the measurement of "assessment involvement." Integratively complex subjects were less enthusiastic about being under continual scrutiny than their integratively simple counterparts. There was some indication, too, that the integratively complex assessees were aware of their less flattering characteristics. They rated themselves relatively low on personality traits such as social compliance, responsibility, and orderliness. These traits are suggestive of behavioral patterns that may have contributed to the personality staff's negative impressions of integratively complex individuals.

Mirror-image personological portraits emerge for the inte-

\footnotetext{
${ }^{9}$ Correlations do not, of course, tell us everything we need to know about the relationships between integrative complexity and other personality variables. Even a substantial correlation-such as that between integrative complexity and the Sensation-Intuition scale of the MBTI-does not allow us to determine, for example, whether highcomplexity subjects scored unusually high on Intuition (with low-complexity subjects clustered in the middle range of the distribution) or whether low-complexity subjects scored unusually high on Sensation (with high-complexity subjects clustered in the middle range of the distribution). To specify the exact functional relationships between integrative complexity and each significant correlate would, however, tax both the patience of the readers and the space constraints of this journal. We explored this issue by calculating the means of each correlate for subjects who scored low, medium, and high on integrative complexity. Results revealed that most correlates had a direct linear relationship with integrative complexity (subjects who scored high and low on integrative complexity are at opposing extremes, with subjects who scored medium on integrative complexity falling in the middle of the distribution on each correlate). Interested readers can request from Randall S. Peterson a table that presents the functional relationship between integrative complexity and each correlate in detail.
} 
Table 4

Factor Loadings of Variables That Correlate Highly With Integrative Complexity

\begin{tabular}{|c|c|c|c|c|c|c|}
\hline \multirow{2}{*}{$\begin{array}{l}\text { Self-report } \\
\text { or observer } \\
\text { data }\end{array}$} & \multirow{2}{*}{$\begin{array}{c}\text { Psychological } \\
\text { instrument }\end{array}$} & \multirow[b]{2}{*}{ Item or scale } & \multicolumn{4}{|c|}{ Factor } \\
\hline & & & I & II & III & IV \\
\hline \multicolumn{7}{|c|}{ Factor I } \\
\hline Observer & CAQ & Has hostility toward others & .87 & .02 & .06 & -.05 \\
\hline Observer & CAQ & Behavior is sympathetic/considerate & -.81 & -.36 & -.12 & .07 \\
\hline Observer & STACL & Resentful & .80 & -.05 & -.02 & -.12 \\
\hline Observer & CAQ & Expresses hostility directly & .73 & .23 & .21 & .02 \\
\hline Observer & CAQ & Critical, skeptical, not easily impressed & .71 & .08 & .27 & .03 \\
\hline Observer & STACL & Vindictive & .71 & .00 & -.01 & -.22 \\
\hline Observer & STACL & Selfish & .69 & .36 & .03 & -.14 \\
\hline Observer & CAQ & Exploits dependency in others & .68 & .04 & .13 & -.18 \\
\hline Observer & STACL & Bitter & -.56 & -.49 & -.08 & .23 \\
\hline Observer & STACL & Reasonable & -.56 & -.49 & -.08 & .23 \\
\hline
\end{tabular}

Factor II

\begin{tabular}{lllrrrr} 
Observer & STACL & Zany & .05 & .79 & .05 & -.03 \\
Observer & STACL & Daring & .25 & .65 & .31 & .14 \\
Observer & CAQ & Dependable and responsible person & -.46 & -.63 & -.14 & .24 \\
Observer & STACL & Rebellious & .39 & .60 & .35 & -.11 \\
Observer & CAQ & Tries to stretch limits & .59 & .59 & .21 & .00 \\
Observer & CAQ & Is unpredictable and changeable & .19 & .59 & .37 & -.10 \\
Observer & STACL & Reliable & -.42 & -.59 & -.09 & .27 \\
Observer & STACL & Civilized & -.34 & -.54 & -.12 & .25 \\
Observer & STACL & Deliberate & .08 & -.53 & -.06 & .23 \\
Self & WEP & Pressure to produce & -.05 & .49 & .00 & .08 \\
Self & CPI & Self-Control Scale & -.26 & -.45 & -.10 & .44 \\
Observer & STACL & Spendthrift & .02 & .30 & -.10 & .00 \\
\hline
\end{tabular}

\section{Factor III}

\begin{tabular}{lllrrrr} 
Self & ACL & Creative Personality Scale & .06 & .00 & .67 & .00 \\
Self & MBTI & Intuitive/Sensing & .08 & -.19 & .65 & -.35 \\
Self & MCPI & Barron Complexity Scale & .19 & .11 & .64 & -.36 \\
Self & CPI & Creativity & .22 & -.03 & .64 & -.22 \\
Observer & STACL & Individualistic & .44 & .33 & .54 & .20 \\
Self & VPI & Artistic & -.02 & .15 & .45 & -.05 \\
Observer & STACL & Courageous & -.09 & .25 & .42 & -.01 \\
Self & B-W & Art Scale & .06 & .29 & .40 & -.15 \\
Observer & STACL & Suggestible & -.22 & .13 & -.40 & -.27 \\
\hline
\end{tabular}

Factor IV

\begin{tabular}{lllrrrr} 
Self & CPI & Achievement via Conformity Scale & -.18 & -.12 & -.08 & .81 \\
Self & MBTI & Judging/Perceiving Scale & .24 & -.05 & .25 & -.71 \\
Self & TR-S & Orderliness Scale & -.15 & -.17 & -.26 & .56 \\
Self & MDRW & Sensitivity to others & -.18 & .17 & .03 & .47 \\
Self & MCPI & Barron Soundness Scale & -.09 & -.30 & .10 & .44 \\
Self & TR-S & Responsibility Scale & .08 & -.16 & -.21 & .40 \\
\hline
\end{tabular}

Note. $\mathrm{CAQ}=$ California Adult Q-Set; $\mathrm{STACL}=$ Staff Adjective Check List; WEP $=$ Work Environment Preference Questionnaire; $\mathrm{CPI}=$ California Psychological Inventory; ACL = Adjective Check List; MBTI = Myers-Briggs Type Inventory; $\mathrm{MCPI}=$ Managerial Composite Personality Inventory; $\mathrm{VPI}=$ Vocational Preference Inventory; B-W = Barron-Welsh Scale; TR-S = Trait Ratings of Self; MDRW = Managerial Dimensions Rating for Assessment Weekend.

gratively simple assessees. Assessment data reveal integratively simple participants to have been warm, giving, orderly, deliberate, self-controlled, and socially compliant-in many respects, ideal "don't-make-waves" participants in the assessment process from the perspective of the assessors. Again, however, there is a price to be paid, this time for conformity and self-control. The unflattering portrait of integratively simple persons shows them to be acquiescent, suggestible, unimaginative, and prone to premature closure in ambiguous or rapidly changing situations. The integratively simple assessees may have been "good subjects," but they did not generate respect for their intellect or dynamism among observers.

Overall, these correlates of integrative simplicity-complexity strikingly resemble the correlates of creativity in the now classic IPSR (formerly the Institute of Personality Assessment and Research) studies of creativity among architects, mathematicians, scientists, and writers (Barron, 1955, 1968). Barron found creative persons to prefer complexity and imbalance, to be more 
personally complex, and to be more independent, self-assertive, and dominant. These correlates of creativity mesh nicely with our results that show integratively complex thinkers to be less agreeable (an unflattering view of personal assertiveness), less conscientious (an unflattering view of independence), more open (a flattering view of thoughtfulness), and more undercontrolled. It remains to be seen, of course, whether (a) the integratively complex MBAs will prosper as creative executives in corporations that value innovation or fail because they antagonize key persons critical to career success and (b) the integratively simple MBAs will prosper in corporate hierarchies that require conformity or fail because they do not display the capacity for flexible and innovative thinking critical to success in an increasingly competitive global economy.

The current pattern of personality correlates cannot be dismissed as an artifactual by-product of statistical associations between integrative complexity and mental ability or between integrative complexity and the trilogy of motives usually assessed from PSE responses: achievement, affiliation, and power. Intelligence (as measured by aptitude tests) apparently played no role as a covariate. Moreover, only one motive, need power, was linked to integrative complexity, and that motive, when controlled statistically by means of partial correlation analyses, eliminated the links between integrative complexity and only one of the factor scores-hardly sufficient to alter the robust patterning of results obtained here.

There are, however, more interesting questions to ask about links between motives and cognitive style, and our intention is to answer them in follow-up longitudinal research. In particular, we will explore the role integrative complexity plays in what McClelland and Boyatzis (1982) term the "leader-motive profile": the tendency for effective leaders to have higher need for power and activity inhibition and lower need for affliation than less effective leaders. One working hypothesis is that integrative complexity plays a role much like activity inhibition in channeling need for power in socially constructive and adaptive directions. Integratively complex MBA students, by definition, should be more attuned to the trade-offs among both intrapsychic motives (task vs. socioemotional leadership and self-assertion vs. sensitivity to others) and organizational values (equality vs. efficiency, benefits of routinization vs. innovation, etc.). Accordingly, these individuals may be better positioned to adjust and fine-tune priorities as personal or business circumstances dictate.

Perhaps the most impressive aspect of the current findings is their coherence across multiple methods for assessing cognitive style, including semiprojective measures, self-report measures, observer personality assessments, and performance in a managerial simulation. Since Vannoy's (1965) discouraging demonstration study, cognitive style researchers have become accustomed to meager correlations among methodologically dissimilar measures of conceptually similar constructs (measures that should, on theoretical grounds, be moderately interrelated). This study reveals cross-method correlations of impressive consistency. These correlations, moreover, hold up across both flattering and unflattering characterizations of assessees. On the positive side, our semiprojective measure of integrative complexity is significantly related to self-report measures of independence, creativity, and flexibility using the $A C L$, the $C P I$, the MBTI, and the MCPI. The semiprojective measure is related to the ratings of the managerial assessors who saw complex assessees as possessing initiative and self-objectivity. Finally, the semiprojective measure is related to ratings of personality assessors who viewed integratively complex assessees as critical, original, individualistic, adventurous, and clever.

The unflattering portrait of the integratively complex also held together across methods. Self-report measures revealed negative correlations with achievement through conformity and socialization on the CPI, Kamp social acquiescence, responsibility and social compliance on the TR-S, and sensitivity to others and assessment involvement on the MDRW. In a similar spirit (although with a distinctly more negative tone), personality observers described (using the CAQ) the integratively complex as unpredictable, irresponsible, exploitative, hostile, distrustful of and unable to arouse liking in other people, and inconsiderate.

In sum, this study reveals a complex pattern of correlates of integrative complexity. There is a substantial kernel of truth to each of the personality portraits of integrative simplicity-complexity. Given the coherence across methods, there is also a substantial kernel of truth to the view that integrative simplicity-complexity assessed using the PSE taps into an aspect of cognitive functioning that manifests itself in responses to selfreport tests, social interactions with personality assessors, and professional interactions in a managerial simulation. Cognitive theorists who emphasize the situation and domain specificity of integrative complexity, including Tetlock (1986, 1989), should explicitly allow for the possibility that, although many people can adjust the integrative complexity of their thinking in response to situational demands, there are limits to the usefulness of this conscious strategy-selection view of social cognition. When people construct stories around the ambiguous pictorial stimuli of the PSE (an operant as opposed to respondent measure of personal functioning), those situational demands largely disappear and we may be able to glimpse assessees' characteristic or preferred ways of thinking about social encounters from the cognitive structure of the stories they tell. Integratively simple thinkers populate their stories with purposive people who move confidently and with minimal ambivalence toward well-defined goals. Integratively complex thinkers generate characters who must grapple with either intrapsychic conflict (balancing competing values) or interpersonal conflict (balancing competing constituencies and interests). Perhaps most intriguing, the variation in story structure across assessees is not random, as the most extreme version of the "situationist" hypothesis would lead one to expect. The cognitive structure of PSE stories is lawfully related to both how assessees respond to a wide range of assessment instruments and to how other people respond to assessees. The trait view of cognitive style still has empirical life.

\section{References}

Atkinson, J. W. (1958). Motives in fantasy, action and society. Princeton, NJ: van Nostrand.

Baker-Brown, G., Ballard, E. J., Bluck, S., deVries, B., Suedfeld, P., \& Tetlock, P. (1992). The integrative complexity coding manual. In C. Smith (Ed.), Handbook of thematic analysis. (pp. 605-611). Cambridge, England: Cambridge University Press.

Barron, F. X. (1955). The disposition toward originality. Journal of Abnormal and Social Psychology, 51, 478-485. 
Barron, F. X. (1968). Creativity and personal freedom. New York: van Nostrand.

Barron, F. X., \& Welsh, G. S. (1960). Welsh Figure Preference Test Manual, research edition. Palo Alto, CA: Consulting Psychologists Press.

Block, J. H., \& Block, J. (1980). The role of ego-control and ego resiliency in the organization of behavior. In W. A. Collins (Ed.), Minnesota Symposium on Child Psychology, 13, 39-101. Hillsdale, NJ: Erlbaum.

Boyatzis, R. E. (1982). The competent manager: A model for effective performance. New York: Wiley.

deVries, B., \& Walker, L. J. (1986). Moral reasoning and attitudes toward capital punishment. Developmental Psychology, 22, 509-513.

Gough, H. G. (1956). Imagination-undeveloped resource. In Research developments in personnel management: Proceedings of the first conference on research developments in personnel management. Los Angeles: Institute of Industrial Relations.

Gough, H. G.(1987).The California Psychological Inventoryadministrator's guide. Palo Alto, CA: Consulting Psychologists Press.

Gough, H. G., \& Heilbrun, A. B., Jr. (1983). The Adjective Check List manual. Palo Alto, CA: Consulting Psychologists Press.

Harvey, O. J., Hunt, D., \& Schroder, H. M. (1961). Conceptual systems and personality organization. New York: Wiley.

Holland, J. L. (1978). Vocational Preference Inventory (7th ed.). Palo Alto, CA: Consulting Psychologists Press.

John, O. P. (1990). The "Big Five" factor taxonomy: Dimensions of personality in the natural language and in questionnaires. In $\mathrm{L}$. A. Pervin (Ed.), Handbook of personality: Theory and research. New York: Guilford Press.

Kohlberg, L. (1981). The meaning and measurement of moral development. Worcester, MA: Clark University Press.

Loevinger, J. (1976). Ego development: Conceptions and theories. San Francisco: Jossey-Bass.

McAdams, D. (1990). The person: An introduction to personality psychology. San Diego, CA: Harcourt Brace Jovanovich.

McClelland, D. C. (1958). Methods of measuring human motivation. In J. W. Atkinson (Ed.), Motives in fantasy, action and society. Princeton, NJ: Princeton University Press.

McClelland, D. C. (1961). The achieving society (lst ed.). New York: Irvington.

McClelland, D. C., \& Boyatzis, R. E. (1982). Leadership motive pattern and long-term success in management. Journal of Applied Psychology, 67, 737-743.

Murray, H. (1938). Explorations in personality. New York: Wiley.

Myers, I. B., \& McCaulley, M. H.(1985). Manual: $A$ guide to the development and use of the Myers-Briggs Type Indicator. Palo Alto, CA: Consulting Psychologists Press.

Peabody, D. (1967). Trait inferences: Evaluative and descriptive aspects [Monograph]. Journal of Personality and Social Psychology, 7, 1-18.

Perry, W. G. (1970). Forms of intellectual and ethical development in the college years. New York: Holt, Rinehart \& Winston.

Pruitt, D. G., \& Lewis, S. A. (1975). Development of integrative solutions in bilateral negotiation. Journal of Personality and Social Psychology, 31, 621-633.

Schroder, H. M. (1971). Conceptual complexity and personality organization. In H. M. Schroder \& P. Suedfeld (Eds.), Personality theory and information processing (pp. 240-273). New York: Ronald.

Schroder, H. M., Driver, M. J., \& Streufert, S. (1967). Human information processing. New York: Holt, Rinehart \& Winston.

Schroder, H. M., \& Suedfeld, P. E. (1971). Personality theory and information processing. New York: Ronald.

Streufert, S., \& Streufert, S. (1978). Behavior in a complex environment. Washington, DC: Winston.

Streufert, S., \& Swezey, R. W. (1986). Complexity, managers, and organizations. San Diego, CA: Academic Press.

Suedfeld, P. (1983). Authoritarian leadership: A cognitive-interaction- ist view. In J. Held (Ed), The cult of power: Dictators in the twentieth century. New York: Columbia University Press.

Suedfeld, P. (1992). Cognitive managers and their critics. Political Psychology, 13, 435-454.

Suedfeld, P., \& Rank, A. D. (1976). Revolutionary leaders: Long-term success as a function of changes in conceptual complexity. Journal of Personality and Social Psychology, 34, 169-178.

Suedfeld, P., \& Tetlock, P. E. (1977). Integrative complexity of communications in international crises. Journal of Conflict Resolution, 21, 169-184.

Suedfeld, P., \& Tetlock, P. E. (1991). Psychological advice about political decision making: Heuristics, biases, and cognitive defects. In P. Suedfeld \& P. E. Tetlock (Eds.), Psychology and social policy (pp. 51-70). New York: Hemisphere.

Sullivan, E. V., McCullough, G., \& Stager, M. (1970). A developmental study of the relationship between conceptual, ego, and moral development. Child Development, 41, 399-411.

Tetlock, P. E. (1979). Identifying victims of groupthink from public statements of decision makers. Journal of Personality and Social Psychology, 37, 1314-1324.

Tetlock, P. E. (1981). Personality and isolationism: Content analysis of senatorial speeches. Journal of Personality and Social Psychology, 41, 737-743.

Tetlock, P. E. (1983). Accountability and complexity of thought. Jour nal of Personality and Social Psychology, 45, 118-126.

Tetlock, P. E. (1984). Cognitive style and political belief systems in the British House of Commons. Journal of Personality and Social Psychology, 46, 365-375.

Tetlock, P. E. (1985). Integrative complexity of American and Soviet foreign policy rhetoric: A time-series analysis. Journal of Personality and Social Psychology, 49, 1565-1585.

Tetlock, P. E. (1986). A value pluralism model of ideological reasoning. Journal of Personality and Social Psychology, 50, 819-827.

Tetlock, P. E. (1989). Structure and function in political belief systems. In A. G. Greenwald \& A. Pratkanis (Eds), Attitude structure and function. Hillsdale, NJ: Erlbaum.

Tetlock, P. E. (1991). An alternative model of judgment and choice: People as politicians. Theory and Psychology, 1, 451-477.

Tetlock, P. E. (1992). The impact of accountability on judgment and choice: Toward a social contingency model. In M. Zanna (Ed.), $A d$ vances in Experimental Social Psychology (Vol. 25, pp. 331-376). San Diego, CA: Academic Press.

Tetlock, P. E., Armor, D., \& Peterson, R. S. (1992). The slavery debate in antebellum America: Cognitive style, value conflict and the limits of compromise. Unpublished manuscript, University of California, Berkeley.

Tetlock, P. E., \& Boettger, R. (1989). Accountability: A social magnifier of the dilution effect. Journal of Personality and Social Psychology, 57, 388-398.

Tetlock, P. E., \& Kim, J. (1987). Accountability and overconfidence in a personality prediction task. Journal of Personality and Social Psychology, 52, 700-709.

Tetlock, P. E., \& Suedfeld, P. (1988). Integrative complexity coding of verbal behavior. In C. Antaki (Ed.), Lay explanation. Beverly Hills, CA: Sage.

Vannoy, J. S. (1965). Generality of cognitive complexity-simplicity as a personality construct. Journal of Personality and Social Psychology, 2, 385-396.

Werner, H. (1948). Comparative psychology of mental development. New York: Science Editions.

Winter, D. G. (1973). The power motive. New York: Free Press.

Received December 2, 1991

Revision received October 16, 1992

Accepted October 17, 1992 